\title{
Associação de Leitura do Brasil (ALB): memória e história em prol da leitura e do livro no Brasil'
}

\section{Brazilian Association of Reading (ALB): memory and history for reading and the book in Brazil}

https://doi.org/10.34112/2317-0972a2020v38n79p17-28

\section{Sônia Midori TAKamatsu²}

RESUMO: O tema deste artigo refere-se às memórias da Associação de Leitura do Brasil (ALB), entidade que, há quase quatro décadas, congrega interesses relativos à leitura e ao livro como interfaces da educação. A associação tem promovido, ao longo dos anos, um conjunto de iniciativas em prol da leitura e do livro no Brasil através de eventos significativos como o Congresso de Leitura do Brasil (COLE) e publicações como a revista Leitura: Teoria e Prática, editada desde 1982. A análise centralizou o período de criação da entidade até sua consolidação, cuja extensão inclui as primeiras edições dos Congressos de Leitura do Brasil (1978 a 1981), a fundação da ALB (1981) e as eleições da primeira diretoria da entidade em 1983. Os referenciais teóricos utilizados aqui como suporte metodológico fazem parte do domínio da História Cultural.

Palavras-chave: Associação de Leitura do Brasil (ALB); leitura; memória.

ABStRAct: The theme of this article refers to the memories of Brazilian Association of Reading (ALB) institution that gathers the interest about reading, the book, and especially the reading and the book as interfaces for education memories. Throughout the years,

1. Originado da pesquisa de Doutorado "Artes de Fazer": memória, participação e história nos 30 anos da Associação de Leitura do Brasil, defendida no Programa de Pós-Graduação em Educação, 2017. A pesquisa integrou também o projeto Associação de Leitura do Brasil - ALB: memórias.

2. Sociedade Pró-Menor de Barão Geraldo, Campinas, São Paulo, Brasil. 
the association has promoted initiatives for the reading and the book in Brazil through significant events such as the Brazilian Reading Congress (COLE) and publications such as the magazine Leitura: Teoria e Prática, published since 1982. The analysis centered the period of creation of the entity until its consolidation, whose extension includes the three first edition of the Reading Congresses of Brazil (1978 to 1981), the foundation of the ALB (1981) and the elections of the first board of the entity in 1983. The theoretical references of this work are part of the Cultural History's field.

Keywords: Associação de Leitura do Brasil (ALB); reading; memory.

\section{A Associação de Leitura do Brasil}

A Associação de Leitura do Brasil (ALB) foi fundada no dia 14 de novembro de 1981 e congregou educadores, pesquisadores, editores, bibliotecários, bibliófilos, artistas e inúmeros colaboradores em torno de sua principal bandeira - o livro, a leitura e a democratização do conhecimento e dos bens culturais. Eventos como o Congresso de Leitura do Brasil (COLE), consolidado como referência no meio acadêmico e para além dele, e publicações como a revista Leitura: Teoria e Prática, editada desde 1982, constituem parte essencial de um conjunto de iniciativas nas quais a chancela da ALB é logo reconhecida. As contribuições de trabalhos sobre leitura que revigoram os debates nos COLEs; as publicações através das quais a ALB faz circular reflexões que contribuem significativamente para a divulgação das experiências de profissionais e a formação de grupos de estudos; o empenho que permitiu à entidade promover ações positivas em prol do livro e da leitura em distintas regiões do país fazem parte de um conjunto de ações que confirmam um percurso que abriu perspectivas para a democratização dos saberes e dos bens de cultura.

A extensa documentação que a entidade conservou ao longo dos anos, assim como as publicações da associação, permite compor uma memória muito útil à constituição de um panorama da trajetória da entidade em favor da leitura e do livro. É nesse sentido que o trabalho de pesquisa procurou operar, e elege como objetivo principal a tarefa de reconstituir, por meio do acervo documental da ALB, a trajetória, as memórias e as iniciativas que a entidade protagonizou. $\mathrm{O}$ período delineado para a pesquisa foi ordenado da seguinte forma: 1) momento anterior à fundação oficial da associação, concomitante à realização das primeiras edições dos COLEs no final da década de 1970; 2) a fundação da entidade, em 1981; 3) período de consolidação 
da entidade, e que remete à gestão da diretoria provisória (1981-1983); 4) as eleições que foram responsáveis por constituir a primeira diretoria para o biênio 1984-1985.

O critério que orientou a delimitação do período para a pesquisa resultou do contato inicial com o corpus pesquisado permitindo que o nosso interesse fosse concentrado na análise de documentos relativos ao percurso inicial da ALB. O extenso conjunto de documentos encontra-se em diversos suportes como impressos, registros em áudio, vídeos, fotos e registros digitais e que permitiu a reunião de um corpus diversificado para a investigação; constitui-se, então, como uma fonte relevante de pesquisa que tem servido como objeto de interesse a pesquisadores, portanto, é presente em trabalhos acadêmicos em curso e que certamente servirá a outras investigações futuras ${ }^{3}$.

Na primeira incursão do trabalho, alcançamos registros importantes sobre a ALB, especialmente aqueles que se relacionavam ao período de criação da entidade - período, a propósito, contemporâneo a um dos momentos mais críticos da história recente do Brasil, os últimos momentos da ditadura militar e os primeiros passos da abertura política no país. Pôde-se constatar, por exemplo, que as questões tomadas como bandeira pela associação - a leitura, o acesso à educação e cultura - traduziam, de forma oportuna, os anseios de profissionais ligados à educação e cultura, num momento em que a sociedade brasileira se mobilizava para a redemocratização da nação. Naquele momento já se fazia evidente as dimensões profundamente negativas na vida brasileira que resultava do golpe de Estado que havia conduzido os militares ao poder e os esforços da ditadura para contemplar as

3. Pesquisadores que participam do projeto Associação de Leitura do Brasil: Memórias tem apresentado produções que corroboram a importância do acervo; o mais recente foi a dissertação de mestrado de Larissa de Souza Oliveira, "Os espaços de leitura nas páginas do Congresso de Leitura do Brasil - COLE (19781993)”, defendida na Faculdade de Educação da Unicamp, em 2018. Há ainda outro trabalho em curso, nível de doutorado, desenvolvido por Renata Aliaga.

Relacionamos trabalhos que foram apresentados em curso de graduação como requisito para a conclusão do curso cuja fonte de pesquisa são publicações e arquivos de documentos de eventos promovidos pela ALB: RITTO, Ana Claudia. Relação "Literatura para crianças e escola nos trinta anos de Congresso de Leitura do Brasil, graduação em Pedagogia - FE/ Unicamp, 2009; SIMIONI, Erica B. "Interesses de leitura e a revista Leitura: Teoria \& Prática”, graduação em Pedagogia — FE/ Unicamp, 20o8; MOMOLI GIACOPINI, Carina M. "A presença da literatura infantil na revista Leitura: Teoria \& Prática”, graduação em Pedagogia - FE/ Unicamp, 2007; MIRANDA, Yasmin de F. B. "Trabalho com jornal em sala de aula: estado da arte”, graduação em Pedagogia — FE/ Unicamp, 2007; PENTEADO, Ariadne Ieza. "Formação docente e a prática do ensino da leitura: contribuições oriundas da revista Leitura: Teoria \& Prática”, graduação em Pedagogia - FE/Unicamp, 2007; SANTANA, Louise Peçanha, " $1{ }^{\circ}$ Congresso de Leitura (1978): constituindo arquivo”, graduação em Pedagogia — FE/Unicamp, 2013; OLIVEIRA, Larissa de S., "A biblioteca escolar entre as páginas escritas do Congresso de Leitura do Brasil e a Revista Leitura: Teoria e Prática (1978 a 1985)”, FE/Unicamp, 2015. 
aspirações das elites. Mantendo a ordem política por meio de medidas opressivas, os militares no poder usavam do mesmo expediente no plano econômico, com o arrocho salarial e a consequente falta de investimentos substantivos em programas que visassem o desenvolvimento econômico e social, sobretudo em áreas como educação, saúde e habitação; tudo isso incentivado pelo capital privado e pelos interesses do capital estrangeiros. ${ }^{4}$ É dentro desse cenário político complexo que podemos compreender a iniciativa de criação da ALB, de um lado, acumulava-se as heranças nefastas de 15 anos de ditadura e, de outro, aumentava a percepção de que a ditadura agonizava e que a perspectiva da democracia se mostrava muito mais possível e concreta. É nele que ganha sentido a disposição e a atuação de um grupo de pessoas interessadas nas questões da educação e da cultura, mobilizadas em torno de iniciativas como o COLE e a criação de uma entidade que levasse tais compromissos à frente. Ou seja, era num cenário de incertezas que um grupo de acadêmicos e profissionais da educação encontrou espaço para o debate de problemas que atingiam setores fundamentais da vida social, especialmente a educação, duramente alvejada por longos anos de políticas questionáveis; o resultado imediato desse panorama foram as péssimas condições para o desenvolvimento e estímulo da leitura entre os alunos e a população em geral.

A democratização da leitura tornou-se o objetivo central da ALB desde a sua criação, orientando suas ações em prol da leitura e do acesso ao livro ou aos bens culturais que permitissem a leitura. Todavia, o sentido e a legitimidade da legenda foram construídos nas edições dos primeiros COLEs, entre 1978 a 1981, que proporcionaram a adesão necessária de um contingente diversificado de pessoas. Os congressos configuraram um importante espaço para os debates em torno das questões ligadas à leitura, mas, sobretudo, ao debate dos problemas no campo educacional e cultural. Exemplo disso viria da realização da mesa-redonda "Divulgação da Cultura”, realizada durante o $1^{\circ}$ COLE, em 1978, quando o professor Moacyr Gadotti ${ }^{5}$ apontou os grandes problemas que o país enfrentava em relação à educação, em especial, a situação aguda de exclusão vivida por grande parte da população, em relação ao sistema educacional e do acesso aos bens culturais.

4. O projeto de desenvolvimento industrial seguiu como a grande meta econômica do regime, não obstante tivesse sido conquistada apenas relativamente (ou setorialmente), e com enorme prejuízo social e político.

5. Moacyr Gadotti professor da Faculdade de Educação da Unicamp na década de 1980 e posteriormente na Faculdade de Educação da USP onde se aposentou. Fundador do Instituto Paulo Freire e atual presidente de honra do instituto. 
A produção de bens, de ideias, de técnicas está, como qualquer outra, vinculada a uma sociedade, e, no nosso caso, a uma sociedade de classes, em que somente uma minoria tem o poder de se apropriar dos bens produzidos pela população. Nesse contexto a questão da divulgação da cultura não é nem pedagógica, nem técnica e sim política. A política em relação à divulgação da cultura tem sido sabotada pela própria distribuição de renda neste país. De 1965 para cá, a verba destinada para o MEC caiu de $11 \%$ para $4 \%$, o que nos situa em último lugar na América Latina em termos de porcentagem destinada à educação. Potencialmente, temos no Brasil 25 milhões de leitores, mas, levando em consideração que o nosso operário trabalha em média 15 horas por dia (não teria condição de ler mesmo se os veículos estivessem ao seu alcance, gratuitamente), e que 50\% dos filhos da classe operária não chegam aos patamares da escolarização (portanto não aprendem a ler), alguns dados positivos não significam nada (CONGRESSO DE LEITURA DO BRASIL, 1978, p. 21-22).

Em sua comunicação, o professor Gadotti destacou as condições precárias que grande parte da população era submetida, especialmente, em relação à educação e aos bens de consumo e que, portanto, a leitura integrava uma difícil realidade da qual grande parte da sociedade estava excluída. Na edição do COLE de 1979, Gadotti retomou a análise, porém de forma mais contundente. Na conferência de encerramento do congresso discorreu sobre a grave situação de grande parte da população excluída de direitos básicos como o acesso à cultura por meio dos livros e sobre a necessidade de politizar o debate a esse respeito.

Seria preciso a meu ver, que esse Congresso de Leitura se transformasse num Congresso de Leitura Popular, que defendesse os interesses dos leitores postergados. Não basta saber ler se os veículos de leitura são inacessíveis, financeira e culturalmente, à massa da população. Ler é uma necessidade social, um bem social, e, portanto, deve ser garantido pelo Estado. O Estado vem se desobrigando, "lenta e gradualmente" da sua tarefa de possibilitar a leitura para todos, entregando-a à empresa particular (CONGRESSO DE LEITURA DO BRASIL, 1979, p. 45).

Na esteira das edições anteriores, o $3^{\circ}$ COLE, em 1981, foi centrado no tema "Lutas pela democratização da leitura" e consolidou as diretrizes pelas quais a entidade foi criada. Dessa forma, é possível afirmar que os propósitos fundamentais da ALB tenham, ao longo das primeiras edições dos COLEs, tomado forma e 
consistência, especialmente com a crescente participação do público formado em sua maioria por educadores que almejavam alternativas para a educação e o restabelecimento da integridade do processo educacional. A reafirmação desses propósitos mereceu especial atenção na primeira edição da revista Leitura: Teoria e Prática em novembro de 1982, com um editorial que trazia os objetivos básicos da recém-criada entidade e convidando os educadores para o engajamento das lutas pela democratização da leitura. Logo no primeiro parágrafo, o editorial do número zero de Leitura: Teoria e Prática não deixava dúvida a respeito de seus propósitos: a revista "[nascia] com o propósito principal de servir como veículo para a comunicação e o intercâmbio entre aqueles que se preocupam com os problemas da leitura em nosso país" e convidava "a todos aqueles que [desejavam] lutar pela democratização da leitura no contexto brasileiro através de um trabalho coletivo e transformador"6.

É diante de tais características de recusa à situação educacional do país naquele momento que aproximamos as ações da ALB (já iniciadas nos primeiros COLEs) aos conceitos de Michel de Certeau que define o caráter ético (CERTEAU, 1985, p. 8) das práticas cotidianas permitindo abrir espaços para as práticas transgressoras de uma ordem imposta: "um espaço que não é fundado sobre a realidade existente, mas sobre uma vontade de criar alguma coisa" (CERTEAU, 1985, p. 8). As orientações para construção da narrativa sobre o percurso e as memórias da ALB apoiaram-se nessas questões colocadas por Certeau. Consideramos que para compor uma narrativa sobre a história da associação seria necessário a observação das práticas cotidianas que o grupo de fundadores da entidade empreendeu nos momentos iniciais da trajetória e que permitiu a criação e fundação da associação; práticas que, a nosso ver, são as artes de fazer, pois derivam da recusa e da transgressão ao autoritarismo e produziram um espaço de militância em torno de objetivos legítimos no campo da educação. Assim, tivemos o interesse em resgatar documentos que nos trazem notícias a respeito dessas práticas e dos próprios discursos sobre a leitura produzidos naquele momento.

As ações da entidade, em torno de objetos como a leitura e o livro, permitiram discutir os sentidos e representações presentes em tais objetos num dado momento, assim como as apropriações dessas representações por um círculo de pessoas. Cabe dizer ainda que algumas noções fundamentais buscadas no suporte teórico da História Cultural são, em nosso entendimento, essenciais à tarefa de observar, investigar e dar

6. Leitura: Teoria e Prática, número zero, novembro de 1982, p. 2. 
a conhecer trajetórias de associações como a ALB e, igualmente, as ações resultantes de sua criação. Segundo afirma Chartier (2002), "a História Cultural, tal como a entendemos, tem por principal objeto identificar o modo como em diferentes lugares e momentos uma determinada realidade social é construída, pensada, dada a ler." (CHARTIER, 2002, p. 16-17). Assim, a apreensão do mundo social pode ser dada a partir de categorias fundamentais, a despeito das variáveis próprias a uma classe ou grupo que são partilhadas pelos seus membros. Ainda segundo o autor, essas representações são distintas e dizem respeito, sobretudo, ao "grupo que as forjam" (CHARTIER, 2002, p. 17). Portanto, decifrar os discursos inerentes às representações é decifrar quem fala e de qual lugar fala, ainda que essas representações suscitem estratégias e práticas para legitimar um discurso e justificar as escolhas feitas pelo grupo.

Dessa relação de práticas e contexto, podemos extrair a matéria para compor uma memória coletiva do grupo, seguindo a definição que Maurice Halbwachs nos oferece. Segundo ele, a memória coletiva diz respeito a uma história vivida por um grupo de pessoas e, igualmente, às apropriações resultantes dessa vivência do grupo; os sentidos e representações atribuídos pelo grupo são singularmente incorporadas pelos membros em determinado tempo e circunstância (HALBWACHS, 2003, p 79). Trata-se de uma concepção da memória coletiva como uma construção social, ou seja, a concepção que vê nas lembranças de fatos, objetos e imagens as marcas das convenções sociais próprias dos grupos (SANTOS, 2012, p. 77). Logo, o entendimento das relações construídas entre os membros do grupo fundador da ALB e os objetivos em comum podem nos auxiliar na compreensão do conjunto de práticas estabelecidas pelo grupo para conduzir seus propósitos e compor a narrativa sobre a trajetória da entidade.

\section{FundAÇÃo DA ALB E A PRIMEIRA DIRETORIA}

A criação da Associação de Leitura do Brasil foi decidida em assembleia com a participação dos congressistas do $3^{\circ} \mathrm{COLE}$ realizada no salão nobre da PUC de Campinas nos dias 13 e 14 de novembro de 1981. Os debates da assembleia deram continuidade às pautas discutidas durante o congresso e resultaram no consenso sobre a importância de uma instância como a ALB, que articulasse e divulgasse, sobretudo para os professores e para os demais profissionais ligados à educação, os trabalhos e pesquisas sobre leitura desenvolvidos em várias regiões do país. Foi eleito em assembleia um comitê provisório para tratar dos trâmites legais da nova entidade e contou com os seguintes membros: o professor Ezequiel Theodoro da 
Silva; Leonídio Balbino da Silva, editor da Livros Irradiantes S/A; Lilian Lopes Martin da Silva, professora da Faculdade de Educação da Unicamp; Marli Pinto Ancassuerd, professora do Centro Universitário Fundação Santo André; Mary Fátima de Lacerda Mendonça, professora da Universidade Federal de Goiás; Olga Molina, professora da Faculdade de Educação da USP; as bibliotecárias Raquel Maria de Almeida Prado e Regina Celi de Souza; e Mariza B. Teixeira Mendes7 . O comitê tinha como tarefas iniciais a elaboração dos Estatutos da ALB, a organização das eleições da primeira diretoria (gestão a partir de 1982), a organização do $4^{\circ}$ COLE em 1982 e a organização da primeira revista sobre leitura ${ }^{8}$. A primeira sede foi

7. Ezequiel Theodoro da Silva, professor da Faculdade de Educação da Unicamp desde 1975, atualmente atua como colaborador da instituição. Foi fundador da ALB e esteve à frente da organização dos COLEs desde sua primeira edição. Um dos pioneiros em pesquisas sobre o tema leitura sua contribuição traduzida em diversas publicações, são referências no campo da educação.

Leonídio Balbino da Silva (1936 -) natural de Alagoas. Em 1959 fundou uma distribuidora de livros e em 1965 fundou a Editora Livros Irradiantes S/A que se transformou em grande editora nos anos de 1980.

Lilian Lopes Martin da Silva é professora da Faculdade de Educação da Unicamp desde 1982 e, atualmente está aposentada. Participou da organização dos COLEs desde sua primeira edição. Fundadora da ALB, fez parte da diretoria da entidade em várias gestões e em diferentes funções. Nos primeiros congressos atuou na organização geral dos eventos, sendo responsável pela edição dos Resumos e Anais. Faz parte, desde o início, do corpo editorial da revista Leitura: Teoria e Prática editada pela ALB. Foi coordenadora do grupo de pesquisas ALLE (Alfabetização, Leitura e Escrita), e, também, do Fórum do Magistério, evento promovido pela ALB em parceria com a Faculdade de Educação da Unicamp. Atualmente coordena o projeto Associação de Leitura do Brasil - ALB: Memórias que integra o grupo de pesquisa ALLE/AULA.

Marli Pinto Ancassuerd, professora do Centro Universitário Fundação Santo André desde 1971, trabalhou com temas sobre educação, principalmente em políticas públicas e educação de jovens e adultos. Atualmente está aposentada e colabora com o grupo de pesquisas GEPEJA (Grupo de Estudos e Pesquisas em Educação de Jovens e Adultos) da Faculdade de Educação da Unicamp.

Mary Fátima de Lacerda Mendonça, professora aposentada da Universidade Federal de Goiás. Atuou na UFG desde 1981 na área de Linguística.

Olga Molina, atualmente professora aposentada da Faculdade de Educação da USP. Na época de fundação da ALB já atuava na instituição como docente. Foi vice-presidente da ALB na gestão da diretoria provisória e nas gestões de 1984-1985 e 1986-1987.

Raquel Maria de Almeida Prado, bibliotecária, professora da PUC de Campinas desde 1971 até sua aposentadoria.

Regina Celi de Souza, bibliotecária, atualmente é presidente do Conselho Federal de Biblioteconomia. Mariza B. Teixeira Mendes publicou um artigo intitulado "Encontro entre alunos de $1^{\circ}$ grau e escritores infanto-juvenis”, na revista Leitura: Teoria e Prática, $\mathrm{n}^{\circ} 1$, de 1983 . À época era professora de $1^{\circ}$ e $2^{\circ}$ graus na cidade de Bauru, São Paulo.

8. O tramite legal para a constituição da associação exigia que houvesse diretoria formalizada e, dessa forma, os membros do comitê provisório compuseram a diretoria provisória para o encaminhamento das formalidades exigidas. A primeira mudança na diretoria provisória ocorreu em abril de 1982, quando o editor Leonídio B. da Silva comunicou seu afastamento do cargo de primeiro tesoureiro; em seu lugar foi indicado o professor 
alocada em caráter provisório na Faculdade de Educação da Unicamp, funcionando nas dependências do Departamento de Metodologia de Ensino.

A primeira versão dos Estatutos ${ }^{9}$ da entidade definia os traços essenciais de organização e estabelecendo as normas para regular as instâncias de decisões previstas pelo documento. De acordo com os Estatutos, a ALB constituía-se como uma entidade sem fins lucrativos composta pelas seguintes instâncias administrativas: uma diretoria eleita pelos associados em assembleia geral; um Colegiado de Representantes formado por membros dos grupos de pesquisas regionais e um Conselho Consultivo composto por 20 membros efetivos da associação. Além da organização das edições do COLE, a entidade passaria a promover um seminário anual de leitura de caráter regional, com a participação dos grupos de pesquisas regionais. Cabe lembrar que as comissões que organizavam os congressos sempre procuravam privilegiar a participação dos professores da rede de ensino, pois viam a importância dessa participação para a efetivação das propostas debatidas durante os eventos. Essa preocupação constava nos Estatutos da entidade na composição do Conselho Consultivo, uma instância que possibilitaria a participação ativa da categoria dentro da nova associação. O Conselho seria formado por 20 membros efetivos $^{10}$ indicados pela diretoria com a apreciação do Colegiado de Representantes. A composição acomodaria professores dos níveis de ensino de $1^{\circ}$ e $2^{\circ}$ graus e pré-escola, além de estudantes universitários e do ensino de $2^{\circ}$ grau. Havia também a participação de outros segmentos na constituição do Conselho Consultivo como editores de livros, bibliotecários e livreiros, com dois membros para cada segmento.

Dentre as ações da diretoria provisória, destacamos a publicação da revista Leitura: Teoria e Prática. A revista é uma das mais duradouras publicações do gênero no país; seu objetivo é estimular a reflexão e o debate sobre as questões da leitura e do livro contemplando variados aspectos que envolvem o tema, visando, sobretudo, à divulgação de trabalhos acadêmicos e experiências de práticas pedagógicas de professores e educadores relacionadas ao universo da leitura. Outra ação relevante foi a organização do $4^{\circ} \mathrm{COLE}$ realizado em novembro de 1983 e constituiu o primeiro evento organizado pela ALB; contou com a parceria da Prefeitura de Campinas e

Hilário Fracalanza, da Faculdade de Educação da Unicamp, e que desde a primeira edição do COLE, em 1978, já colaborava e participava da organização dos eventos.

9. A primeira versão dos Estatutos da ALB foi elaborada pela diretoria provisória e aprovada em assembleia pelos associados durante a 4 edição do COLE em 1983.

10. Membro efetivo é a designação aos associados da ALB. 
do Centro de Leitura da Faculdade de Educação da Unicamp, sob a coordenação do professor Ezequiel T. da Silva. A edição foi marcada pela reiteração dos propósitos da nova entidade e propunha uma ampla discussão em torno de propostas e alternativas que pudessem compor um programa de diretrizes para uma política pública de desenvolvimento da leitura.

A última tarefa designada para a diretoria provisória foi a organização e realização da primeira eleição da entidade visando eleger os membros da diretoria efetiva. As eleições foram convocadas em 1983 e o processo representou um importante passo para a consolidação da entidade. Previsto nos Estatutos, o processo eleitoral elegeria uma diretoria que ficaria à frente da entidade por um período de dois anos. A cada edição do $\mathrm{COLE}^{11}$, em assembleias ordinárias realizadas durante o evento haveria a posse dos eleitos. A primeira diretoria eleita respondeu pelo biênio de 1984 e 1985.

\section{Alguns apontamentos}

Os Congressos de Leitura do Brasil foram decisivos para a criação da Associação de Leitura do Brasil, pois cada edição engendrava um espaço privilegiado de debates sobre a leitura bem como uma iniciativa aglutinadora de pesquisadores, professores e profissionais interessados no tema. Os COLEs foram relevantes não somente pelos debates a respeito da leitura, mas porque eram também inovadores em seu formato. A iniciativa de prover um espaço para reflexão e discussão sobre o tema aliada a eventos como a Feira do Livro, inaugurou uma chancela que, ao longo do tempo, viria a se tornar referência distintiva ${ }^{12}$. Cabe mencionar o professor Wanderley Geraldi ${ }^{13}$ que definiu acertadamente a natureza do COLE como democrática e destinada para profissionais da educação, além disso o evento é "aberto às falas e escutas [onde] soam bem as vozes dos professores com suas vivências e suas

11. Os Congressos de Leitura do Brasil passaram a ser bianuais a partir da $3^{\mathrm{a}}$ edição em 1981.

12. O nascimento do COLE pode ser compreendido a partir do projeto "Feira do Livro" elaborado por professores do DEME da Faculdade de Educação. O Congresso integrou a "Feira do Livro” - espaço destinado à exposição de livros com a participação de editores, livreiros e que visava à aproximação da comunidade com a literatura, pressuposto básico do projeto para o desenvolvimento do hábito da leitura. Além disso, a integração também objetivava reflexões a respeito dos "problemas relacionados ao consumo de literatura" (Projeto Feira do Livro, 1978, p. 2). Outro segmento realizado durante o período da Feira

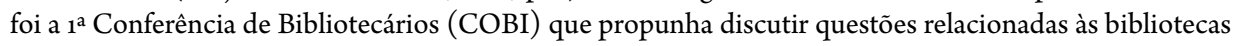
escolares e o incentivo ao hábito de leitura vinculado ao espaço da biblioteca. $\mathrm{O}_{1}^{\circ} \mathrm{COBI}$ não constava como segmento previsto no projeto Feira do Livro, mas foi oficializado na programação do evento.

13. Wanderley Geraldi, professor do Instituto de Estudos da Linguagem (IEL) da Unicamp. 
preocupações, como soam bem as vozes supostamente mais informadas e conformadas aos moldes da academia" ${ }^{14}$.

Nesse sentido, podemos depreender, por fim, que os movimentos empreendidos pelo grupo organizador do $1^{\circ} \mathrm{COLE} /$ Feira do Livro $/ 1^{\circ} \mathrm{COBI}$ em 1978 , configuraram um conjunto de recursos que permitiu ocupar o espaço do evento de forma democrática num momento relevante da história do país. O final dos anos de 1970 - período do processo de abertura política do país - foi um período que exigiu da sociedade, ativa participação nas lutas por uma sociedade mais justa, com garantias às liberdades individuais e condições de vida mais dignas para a população. Os diversos segmentos mobilizados foram decisivos no que diz respeito ao cenário político, e os educadores não estiveram alheios ao chamado - seja nas lutas por melhorias de condições de trabalho, seja na reivindicação de maior participação nos processos decisórios a respeito dos rumos da educação no país. Dentro desse panorama, consideramos que as primeiras edições dos COLEs se constituíram como um fórum onde profissionais da educação, que enfrentavam uma realidade cotidiana bastante adversa, puderam debater problemas comuns e encontrar alternativas no âmbito coletivo.

\section{REFERÊNCIAS}

CERTEAU, Michel de. Teoria e Método no Estudo das Práticas Cotidianas. In: SZMRECSANYI, Maria I. (Org.). Anais do Encontro "Cotidiano, Cultura Popular e Planejamento Urbano". São Paulo: FAU/USP, 1985. p. 3-19.

CHARTIER, Roger. A beira da falésia: a história entre certezas e inquietude. Porto Alegre, RS: Editora da UFRGS, 2002.

CHARTIER, Roger. História Cultural: entre práticas e representações. Tradução de Maria Manuela

Galhardo. 2. ed. Portugal: DIFEL, 2002.

HALBWACHS, Maurice. A memória coletiva. Tradução de Beatriz Sidou. São Paulo: Centauro, 2003. SANTOS, Miryam S. Memória Coletiva e teoria social. São Paulo: Annablume, 2012.

\section{Resumos dos Congressos de Leitura do Brasil - COLE}

CONGRESSO DE LEITURA DO BRASIL (1., 1978, Campinas, SP). Resumos. Campinas, SP: UNICAMP, 1979. $99 \mathrm{p}$.

14. "Por trás do COLE”, mensagem do professor João Wanderley Geraldi na mesa redonda "Sentidos da ALB", mesa em comemoração aos 30 anos da Associação de Leitura do Brasil (ALB) em 17 de julho de 2012, 18 COLE, Faculdade de Educação da Unicamp. (acesso no site: https://www.fe.unicamp.br/ead/galerias/1477). 
CONGRESSO DE LEITURA DO BRASIL (2., 1979, Campinas, SP). Resumos. Campinas, SP: UNICAMP, $1980.56 \mathrm{p}$.

CONGRESSO DE LEITURA DO BRASIL (3., 1981, Campinas, SP). Resumos. Orientação de Ezequiel Theodoro da Silva; Revisão de Lilian Lopes Martins da Silva. Campinas, SP: UNICAMP, 1981. $124 \mathrm{p}$.

CONGRESSO DE LEITURA DO BRASIL (4., 1983, Campinas, SP). Resumos. Orientação de Lilian Lopes Martins da Silva e Hilário Fracalanza; Revisão de Ezequiel Theodoro da Silva. Campinas, SP: UNICAMP, 261p.

CONGRESSO DE LEITURA DO BRASIL. "Programa geral: Feira do Livro”, $1^{\circ}$ Congresso de Leitura do Brasil, $1^{a}$ Conferência dos Bibliotecários, 1978 (impresso digitalizado).

\section{SOBRE A AUTORA}

Sônia Midori Takamatsu é graduada em Psicologia (USP), tem mestrado em Educação (UNICAMP) e doutorado em Educação (UNICAMP). É psicóloga da Sociedade Pró Menor de Barão Geraldo e pesquisadora do Grupo de pesquisa "Alfabetização, Leitura e Escrita/Trabalho Docente na Formação Inicial" (UNICAMP). Tem experiência na área de Psicologia com ênfase em Psicologia da Educação e integra o grupo de pesquisadores que organiza o acervo dos Congressos de Leitura do Brasil - Fundo COLE - no Centro de Memória da Faculdade de Educação da UNICAMP.

E-mail: sonia.takamatsu@gmail.com.

Recebido em 27 de abril de 2020 e aprovado em 29 de junho de 2020 . 